\title{
Progressive Failure and Fracture Mechanism of Sandstone under Hydraulic-Mechanical Coupling
}

\author{
Yingming Li $\mathbb{D}^{1,},{ }^{1,2}$ Gang Liu $\mathbb{D}^{1},{ }^{1,3,2}$ Tao Qin $\mathbb{D}^{3},{ }^{3}$ Zhupeng Jin $\mathbb{D}^{3},{ }^{3}$ Chengxing Zhao $\mathbb{D}^{1,2}$ \\ and Shunjie Huang $\mathbb{D}^{1,2}$ \\ ${ }^{1}$ State Key Laboratory of Mining Response and Disaster Prevention and Control in Deep Coal Mines, \\ Anhui University of Science and Technology, Huainan 232001, China \\ ${ }^{2}$ School of Energy and Safety Engineering, Anhui University of Science and Technology, Huainan 232001, China \\ ${ }^{3}$ Heilongjiang Ground Pressure \& Gas Control in Deep Mining Key Lad, Heilongjiang University of Science \& Technology, \\ Haerbin 150022, China \\ Correspondence should be addressed to Gang Liu; 814449714@qq.com
}

Received 29 July 2020; Revised 1 September 2020; Accepted 17 September 2020; Published 30 September 2020

Academic Editor: Qing Ma

Copyright (C) 2020 Yingming Li et al. This is an open access article distributed under the Creative Commons Attribution License, which permits unrestricted use, distribution, and reproduction in any medium, provided the original work is properly cited.

\begin{abstract}
Hydraulic coupling often leads to progressive rock failure accidents. Mechanical tests were performed over a range of combined pore water pressure and confining pressure stress path conditions to study the progressive failure characteristics of sandstone under hydraulic-mechanical coupling and explore the crack initiation and pore water fracture mechanism. The closure stress and damage stress were determined by the axial deformation stiffness and volume deformation stiffness. The experimental results indicate that confining pressure is the main controlling factor in the crack propagation stage, and pore water pressure enhances crack evolution. With increasing effective confining pressure, the effective peak deviatoric stress strongly increases and the characteristic stress increases linearly. The initiation stress and damage stress decrease with increasing pore water pressure. The moduli in stages I, II, and III are similar to the law of the transverse and radial deformation ratio with notable differences in stage IV. The fracture trend angle was determined by the ratio of axial crack strain and radial crack strain. Compared with the experimental results, the internal cracks in the sandstone samples are mainly type-II cracks, and type-I cracks are also locally present. After stress damage, the cracks expand and extend at an angle close to the real fracture.
\end{abstract}

\section{Introduction}

The excavation of underground space disrupts the dynamic balance of underground aquifers, and rock mass environmental diversity and structural complexity increase with depth. In particular, the increasing distribution and pressure of groundwater lead to a coupling of ground stress and groundwater, which is an essential factor that affects underground engineering stability and structural safety [1]. Statistical analysis indicates that more than 200 coal mines are threatened by water disaster. Sandstone undergoes physical, chemical, and mechanical processes under pore water action that result in structural loosening, particle slippage, and crack initiation and propagation, all of which reduce the structural bearing capacity [2], and ultimately induce local or overall instability that can lead to engineering disasters. Such accidents are principally attributed to the evolution of rock cracks, in which water and water pressure play an important role [3]. To ensure the stability of rock mass engineering under pore water pressure, the mechanical property changes of rock mass under water-rock coupling conditions require thorough investigation on the fracture mechanism of water-bearing rock mass problems to provide a scientific basis for sandstone models under hydraulic-mechanical coupling conditions. Pore water experiments are typically used to study the progressive failure process and fracture mechanism of sandstone. These processes pose a significant problem that requires urgent solution for water-rich and high-pressure water projects to provide a theoretical basis for water-rock coupling in engineering applications. 
Pore water pressure affects the effective stress of a rock mass. The continuous migration of pores and cracks thus changes the initiation area and crack expansion direction, which critically impact the rock mechanical properties [4]. Chen and Lei [5] performed creep experiments under complex thermal-hydraulic coupling conditions and determined the influence of temperature and water pressure on the creep rate. Lyu and Lin [6] studied rock creep under pore water action characteristics and determined the degradation process of the rock strength parameters. Liu et al. [2] conducted experiments to address hydraulic coupling and rheological damage and obtained soft rock stress-strain, internal damage evolution, and surface damage rules. Wang et al. [7] used field monitoring to obtain the volumetric water content, pore water pressure, surrounding rock stress (earth pressure), dome settlement, and horizontal convergence. Numerical simulations were also performed to study the deformation law of red clay surrounding rock considering hydraulic-mechanical coupling effects. The stressstrain curve, strength, deformation characteristics, and failure modes of sandstone specimens with saturated pores under different confining pressures and stress levels have also been analyzed [8]. Mu and Yu [9] analyzed the stressstrain relationship and acoustic emission (AE) stress of hydraulically coupled sandstone. The AE characteristics were analyzed, and the hydraulic-mechanical coupling biaxial model of discrete element particle flow was established to study the AE and energy evolution of sandstone. Zhang [10] studied the influence of water content on rockbursting and established an instability criterion. Xie et al. [11] studied the effect of pore water on rock fracture deformation and hydraulic conductivity. The derivation of rock cracks is a process quantity. Zhu et al. [12] analyzed the crack initiation stress of granite and studied the relationship between crack type, crack initiation angle, and confining pressure. Liu et al. [13] defined the characteristic stress of progressive rock failure according to the active state of internal rock cracks, analyzed the elastic parameters of each stage, and established a corresponding constitutive model. Wang et al. [14] studied the progressive failure process of red sandstone under different stress conditions and determined the characteristic stress change law. Li et al. [15] conducted experiments on shale bedding under different confining pressure conditions, studied the change law of personal stress, and analyzed the shale cracking mechanism. Liu et al. [16-18] studied the mechanical characteristics and AE law of rock mass under different water content conditions and stress forms. They analyzed the precursory characteristics of fractures from different angles and discussed the mechanical postpeak unloading law. Several studies have addressed water-rock coupling and progressive rock failure research/calculation methods and constitutive relations. However, the relationship between pore water pressure and progressive rock failure remains poorly understood. These factors specifically influence rock mechanical properties and pore water positively influences the development and expansion of microcracks. In-depth research on the dual influence of hydraulic-mechanical coupling during progressive sandstone failure is thus required.
To explore the rock cracking mechanism under pore water action, it is necessary to obtain the crack activity state of the rock at different stress levels. We conducted triaxial experiments on sandstone under different pore water pressure conditions and combined stress paths of confining pressure. The characteristic stresses (e.g., closing stress, initiation stress, and damage stress) are determined by crack strain, and the relationship between pore water pressure and characteristic stress is explored. We analyze the fracture mechanism of sandstone under hydraulic-mechanical coupling and determine the fracture trend angle by the axial crack strain and radial crack strain ratio. The actual fracture angle and fracture trend angle are compared and analyzed.

\section{Experimental Study of Pore Water Sandstone Characteristic Stress}

2.1. Sample Preparation. To prevent the impact of sample dispersion, yellow sandstone samples were selected from a larger piece of rock. A coring machine was used to drill each sample with a diameter of $50 \mathrm{~mm}$. A cutting machine sawed each sample to a length of $100 \mathrm{~mm}$. According to the experimental specifications and standards, the sample end face was polished to assess particle uniformity. The average density was $2.19 \mathrm{~g} / \mathrm{cm}^{3}$, and the $p$-wave velocity ranged between 1953 and $2043 \mathrm{~m} / \mathrm{s}$ (Figure 1). Each rock has a specific characteristic wave velocity that reflects its mineral composition and internal structure and is also used to verify consistent specimen properties. The typical sample information is listed in Table 1.

\subsection{Experimental Equipment and Procedures. Triaxial} compression deformation experiments of sandstone were conducted under different pore water pressures. The leading equipment was a French TOP ROCK600-50 adaptive multifield coupling triaxial tester, which has three sets of independent loading pumps and main technical parameters. The axial force was $\leq 600 \mathrm{kN}$, the confining pressure was $\leq 60 \mathrm{MPa}$, and the pore water pressure was $\leq 60 \mathrm{MPa}$. The system automatically collects force and displacement data during the loading process and can precisely control the stress, displacement, deformation, and flow, as shown in Figure 2.

In the triaxial pore water experiments, hydrostatic pressure was first applied at a loading rate of $6 \mathrm{MPa} / \mathrm{min}$ until reaching a predetermined value $(10,20$, and $30 \mathrm{MPa})$ and held for $420 \mathrm{~s}$. The pore water pressure was applied at a loading rate of $20 \mathrm{MPa} / \mathrm{min}$ until reaching the set value (5, 10 , and 20) and held for $3600 \mathrm{~s}$ of stabilization to ensure continuous and stable water seepage at the water outlet and stability of the water flow curve. The pressure rapidly stabilized, whereas the pore water required individual seepage and seepage stages and thus longer durations. The deviator was loaded at a rate of $60 \mathrm{MPa} / \mathrm{min}$ until the sample failed. Figure 3 shows the experimental path. After the experiment, photographs were collected of the damaged samples, and broken blocks were collected and wrapped with rubber bands to observe the damage morphology. Each group 


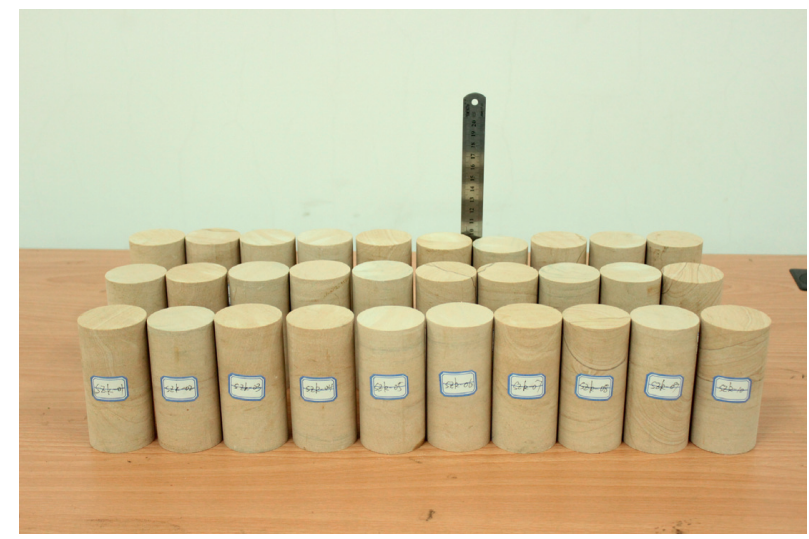

Figure 1: Preparation of sandstone samples.

TABLE 1: Basic information on samples and experiments.

\begin{tabular}{lcccccccc}
\hline Number & $\begin{array}{c}\text { Diameter } \\
(\mathrm{mm})\end{array}$ & $\begin{array}{c}\text { Length } \\
(\mathrm{mm})\end{array}$ & $\begin{array}{c}\text { Quality } \\
(\mathrm{g})\end{array}$ & $\begin{array}{c}\text { Density } \\
\left(\mathrm{g} / \mathrm{cm}^{3}\right)\end{array}$ & $\begin{array}{c}\text { P wave } \\
\text { velocity } \\
(\mathrm{m} / \mathrm{s})\end{array}$ & $\begin{array}{c}\text { Confining } \\
\text { pressure } \\
(\mathrm{MPa})\end{array}$ & $\begin{array}{c}\text { Pore water } \\
\text { pressure } \\
(\mathrm{MPa})\end{array}$ & $\begin{array}{c}\text { Loading speed of the } \\
\text { shaft and confining } \\
\text { pressure }(\mathrm{MPa} / \mathrm{min})\end{array}$ \\
$\begin{array}{l}\text { loading speed } \\
(\mathrm{MPa} / \mathrm{min})\end{array}$ \\
\hline $10-5$ & 49.63 & 100.29 & 424.8 & 2.19 & 1953 & 10 & 5 & 60 \\
$20-5$ & 49.59 & 98.82 & 416 & 2.18 & 2022 & 20 & 5 & 20 \\
$30-5$ & 49.59 & 99.44 & 422.2 & 2.20 & 1980 & 30 & 5 & \\
$20-10$ & 49.6 & 99.21 & 422 & 2.20 & 1976 & 20 & 10 & \\
$30-10$ & 49.75 & 100.78 & 425.4 & 2.17 & 1992 & 30 & 10 & \\
$30-20$ & 49.78 & 100.5 & 425.8 & 2.18 & 2043 & 30 & 20 & \\
\hline
\end{tabular}
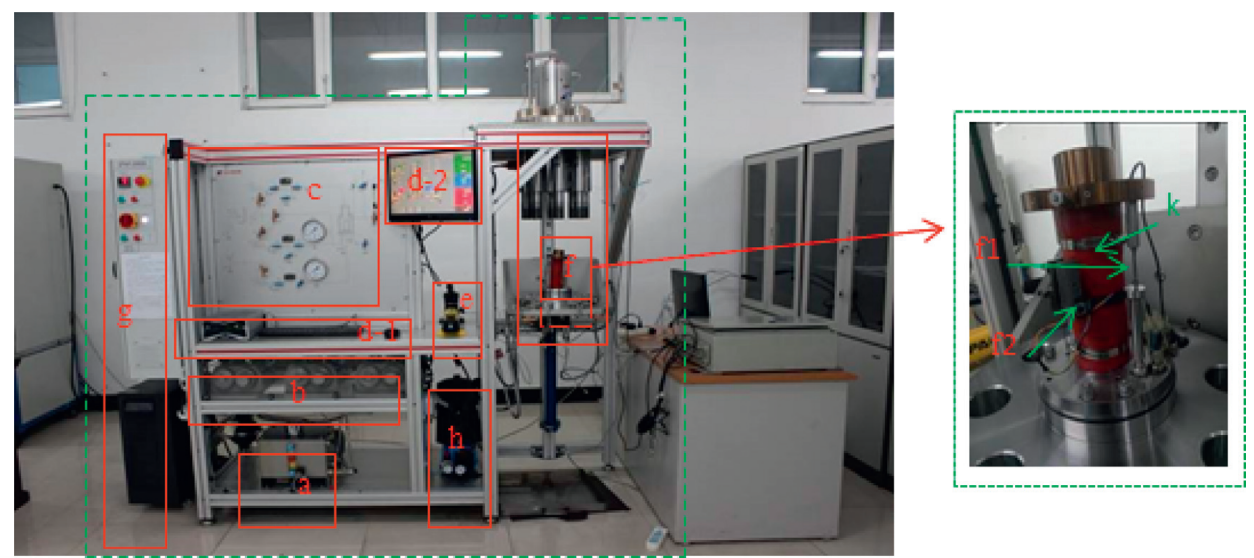

FIGURE 2: Rock mechanics experimental system. a -oil source, b -axis, enclosure, pore water loading pump, c-monitor and control panel, $\mathrm{d}$-computer acquisition control system, e -base lift pump, $\mathrm{f}$-base ( $\mathrm{f}-1$ axial sensor, $\mathrm{f}-2$ radial sensor), $\mathrm{g}$-power, $\mathrm{h}$-pressure pump for confining pressure room.

consisted of three samples. If the peak intensity dispersion was large, the samples were supplemented to continue the experiment path. The samples were labeled according to their confining pressure-pore water pressure (e.g., sample $10-5$ indicates that the surrounding rock confining pressure and pore water pressure were 10 and $5 \mathrm{MPa}$, respectively). Figure 4 shows the stress-strain curve of a typical sample. Preliminary analysis showed that the curve law is visible, which provides a suitable data basis for characteristic stress analysis.

\section{Progressive Failure Process Analysis and Significance of Critical Stress}

There were numerous original cracks in the sandstone samples and the crack evolution process exhibited significant differences under different stress states. The life cycle of the cracks underwent closure, initiation, expansion, connection, and penetration to form a master crack, as shown in Figure 5. According to the crack development process, the primary microcracks and fractures closed during the initial 


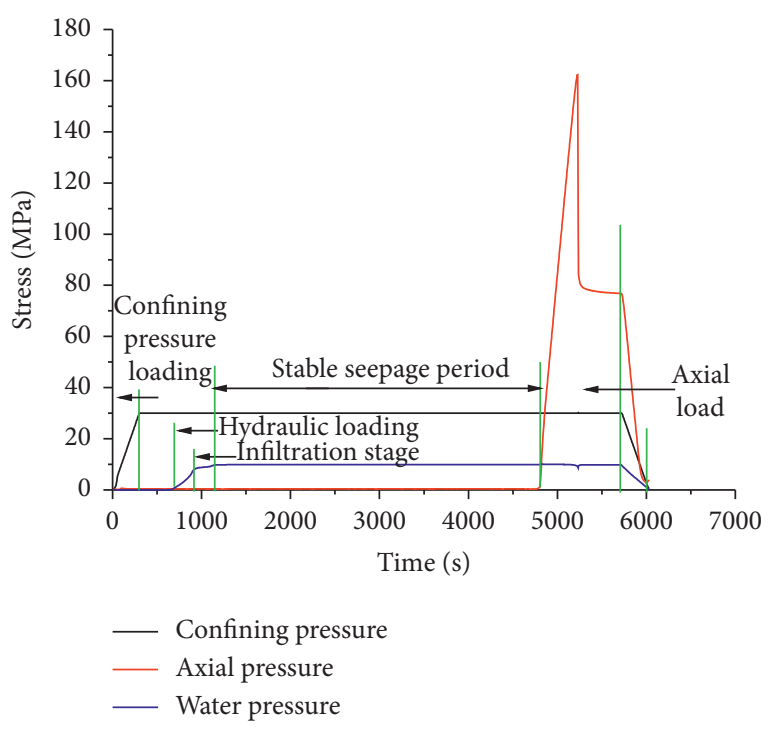

Figure 3: Experimental loading path.

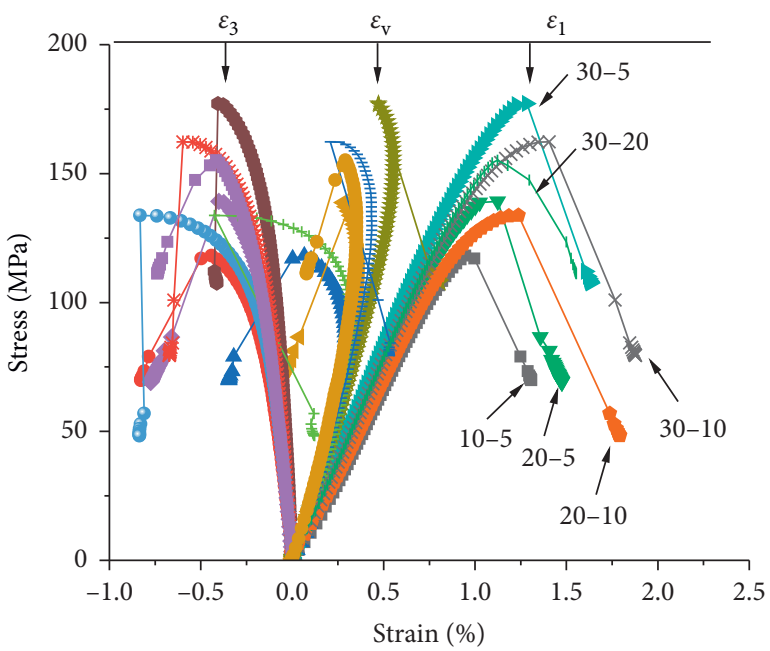

Figure 4: Stress-strain curves under variable pore water and confining pressures conditions.

loading. Upon increasing stress, the entire rock showed elastic deformation characteristics, the cracks were not located, and compressive deformation was the dominant deformation form. After further loading, stable new cracks initiated and propagated in the rock. After continuous loading, most of the microregions reached the ultimate bearing capacity, thus crack propagation, extension aggregation, and crack activity were increasingly active and the rock achieved its overall bearing capacity as through-cracks continued to form.

The characteristic stress of progressive sandstone failure can be divided into four stages: closure stress $\left(\sigma_{c c}\right)$, crack initiation stress $\left(\sigma_{c i}\right)$, damage stress $\left(\sigma_{c d}\right)$, and peak stress $\left(\sigma_{c}\right)$, which correspond to the four stages of the stress-strain curve. Under the initial stress (I), the original crack is entirely closed and the corresponding closed stress $\sigma_{c c}$ is shown in Figure 1(b). As the stress increases (II), the bulk rock obeys Hooke's law and the crack is relatively stable. However, at the end of stage II and beginning of stage III, the first cracks gradually expand and new cracks appear in local areas. At this time, the cracks are in a stable growth stage and the corresponding stress is the crack initial stress $\sigma_{c i}$, which is one of the critical parameters for rock evaluation. These parameters not only characterize the beginning of crack propagation but also indicate the onset of rock volume expansion.

There is a corresponding relationship between the crack initiation stress and expansion point. At this time, both the original crack propagation and new crack initiation are biased toward the main crack. The growth rate of the transverse crack is therefore gradually higher than the axial direction and the volumetric strain begins to shift. The volume is gradually reduced with increasing load. At this time, the cracks are in an unstable growth stage, and the corresponding stress is the damage stress $\sigma_{c d}$. The crack activity becomes increasingly intense, and the extension and growth speed increases until reaching the peak stress. The cracks later form via penetration that cuts the rock blocks into broken bodies.

\subsection{Characteristic Stress and Its Determination Method.}

The rock fracture process is a direct manifestation of the degree of crack activity. This process is essentially a gradual reduction of the rock cohesive force due to crack propagation, after which the process gradually decreases and strength is lost. Nonlinear characteristics that appear after the rock exceeds the closing stress are completely controlled by the microcrack activity. Understanding the stress characteristics of different crack intervals is of great significance for the in-depth study of crack damage and destruction. The International Society for Rock Mechanics has not yet recommended methods for the formation of closure stress, crack initiation stress, and damage stress. Extensive studies have addressed the determination of closure stress, crack initiation stress, and damage stress, which are divided into three categories depending on the method. These include direct observation methods (e.g., computed tomography (CT) and scanning electron microscopy) [19, 20], AE methods [21, 22], and crack strain methods [12, 23, 24]. Due to the Kaiser effect during rock loading, the use of $\mathrm{AE}$ characteristic parameters to distinguish characteristic stress imposes a distortion problem. We therefore used the strain method to determine the characteristic stress.

3.2. Crack Strain Calculation. The volume of a rock will change under stress. Volumetric strain consists of two parts: recoverable elastic deformation and irreversible plastic deformation. Irreversible plastic deformation is mainly caused by the closure of primary microcracks or the initiation and expansion of new cracks. The data monitored by the deformation measurement system represent the total strain. According to the literature [25], the relationship between volumetric strain, axial strain, and radial strain is given as 


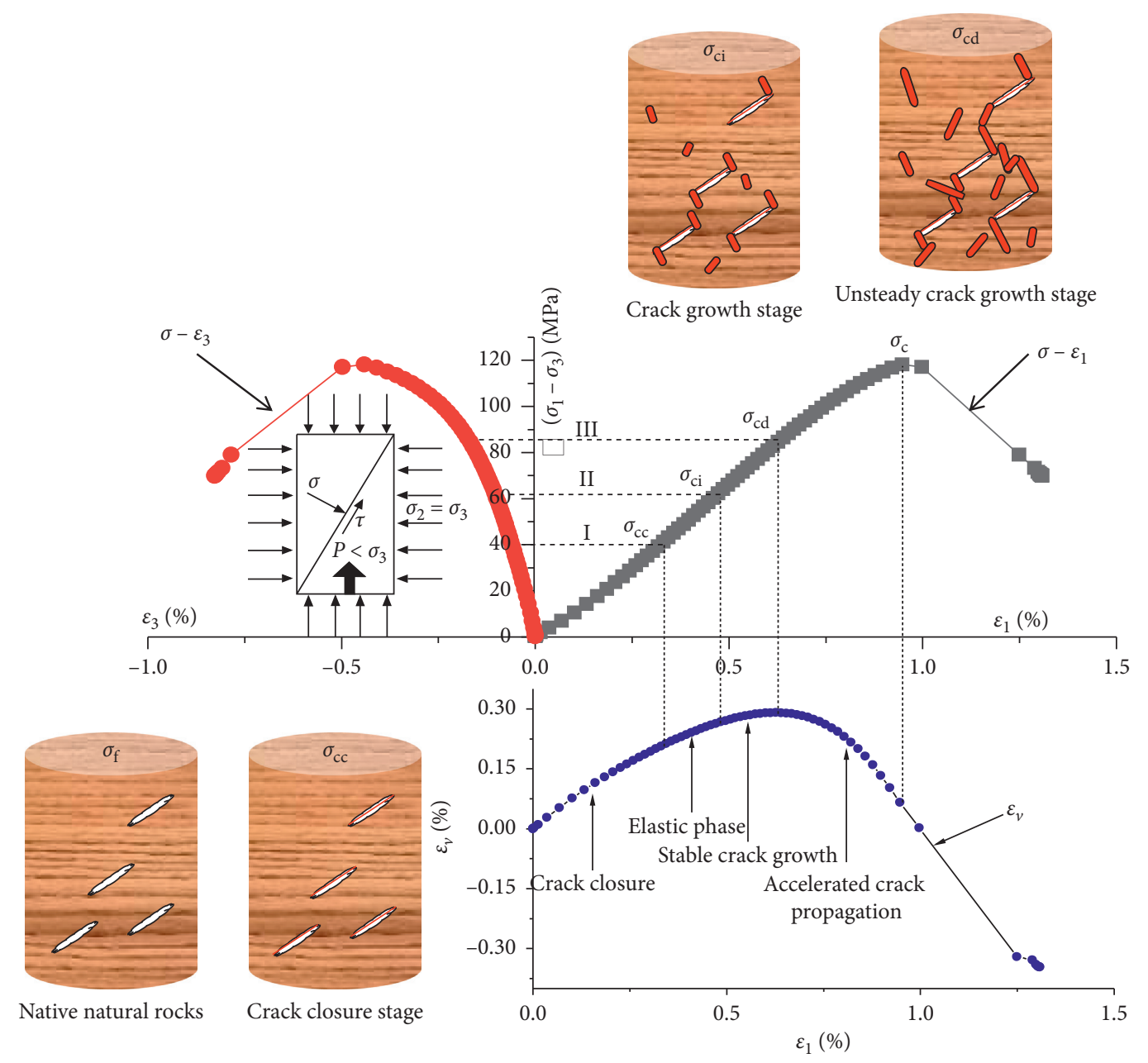

FIGURE 5: Crack initiation stress and initiation propagation and schematic diagram.

$$
\varepsilon_{v}=\varepsilon_{v}^{e}+\varepsilon_{v}^{c}=\varepsilon_{1}+2 \varepsilon_{3}
$$

where $\varepsilon_{v}$ is the total body strain, $\varepsilon_{v}^{e}$ is the elastic body strain, $\varepsilon_{v}^{c}$ is the volume crack strain, $\varepsilon_{1}$ is the total axial strain, and $\varepsilon_{3}$ is the total radial strain.

According to the generalized Hooke's law considering pore water effects, the effective partial stress elastic volume strain under triaxial conditions [9] is

$$
\varepsilon_{v}^{e}=\frac{1-2 v}{E}\left[\left(\sigma_{1}-p\right)+\sigma_{3}\right]
$$

where $v$ is Poisson's ratio, $E$ is the elastic modulus, $\sigma_{1}$ is the axial stress, $P$ is the pore water pressure, and $\sigma_{3}$ is the confining pressure. A simplification of equation (2) yields the elastic strain under the effective axial stress:

$$
\varepsilon_{v 1}^{e}=\frac{1-2 v}{E}\left(\sigma_{1}-p\right)
$$

where $\varepsilon_{v 1}^{e}$ is the axial elastic strain.

The volume strain of the closed or opened crack $\varepsilon_{\text {, }}^{c}$ can be obtained by subtracting the elastic volume strain $\varepsilon_{v 1}^{e}$ from the total volume strain $\varepsilon_{v}$. Axial crack strain can also be calculated following this approach. By incorporating equation (1) into (2) and (3), the formulations for axial crack strain (5) and volume crack strain (4) can be obtained. The radial crack strain is generated under axial stress and cannot be directly calculated. The theoretical relationship between the volume strain, axial crack strain, and radial crack strain is thus obtained by the consistency of the volume strain with the axial strain and radial strain. The radial crack strain is obtained by subtracting the axial crack strain from the calculated volume crack strain. According to the relationship between volume crack strain, axial crack strain, and radial crack strain, equation (6) is therefore transformed to obtain equation (7). The radial crack strain is thus calculated, and the specific relationship is as follows:

$$
\begin{aligned}
\varepsilon_{v}^{c} & =\varepsilon_{1}+2 \varepsilon_{3}-\frac{1-2 v}{E}\left[\left(\sigma_{1}-p\right)+\sigma_{3}\right], \\
\varepsilon_{v 1}^{c} & =\varepsilon_{1}-\frac{1-2 v}{E}\left(\sigma_{1}-p\right), \\
\varepsilon_{v}^{c} & =\varepsilon_{v 1}^{c}+2 \varepsilon_{v 3}^{c}, \\
\varepsilon_{v 3}^{c} & =\frac{\left(\varepsilon_{v}^{c}-\varepsilon_{v 1}^{c}\right)}{2},
\end{aligned}
$$

where $\varepsilon_{v 1}^{c}$ and $\varepsilon_{v 3}^{c}$ are the axial and radial crack strains, respectively. 


\subsection{Crack Strain to Determine Characteristic Stress}

3.3.1. Determination of Closing Stress $\sigma_{c c}$ and Damage Stress $\sigma_{c d}$. Only a few studies have addressed closure stress $\sigma_{c c}$ and damage stress $\sigma_{c d}$. The closure stress $\sigma_{c c}$ is the endpoint where the axial strain enters linearity. The damage stress $\sigma_{c d}$ corresponds to the expansion point of the volumetric strain. However, the inflection point determined by the intuitive judgment of the stress-strain curve trend is not sufficiently accurate and contains considerable arbitrariness. The key to determining $\sigma_{c c}$ and $\sigma_{c d}$ is to identify the curve inflection point. Using the moving point regression technique suggested by Xue et al. [24], $\sigma_{c c}$ and $\sigma_{c d}$ are determined by the axial and volume stiffness, which appropriately refer to the stress-axial strain-bulk strain curve.

From loading to failure, the rock axial stiffness initially increases (compaction stage I), then stabilizes (elastic stage II), and decreases (plastic stage III and postpeak stage) (Figure 6(a)). The back axial stiffness is similar to that of the prepeak elastic stage. The axial stiffness change process continuously evolves. The endpoint of the compaction stage and starting point of the elastic stage (curve inflection point) are the boundary points. The boundary point of axial stiffness is located on the axial stress-strain curve. The value corresponding to the intersection of the curves is $\sigma_{c c}$, which is $27.44 \mathrm{MPa}$ for sample $10-5$. The damage stress is the stress at the moment when the volumetric strain changes from the compressed state to the expanded state. Figure 6(b) shows the deviatoric stress-volume stiffness-volume strain curve. The bulk stiffness data fluctuate between a deviatoric stress of 68 and $88 \mathrm{MPa}$. However, the sign of the stiffness only changes once where the volume stiffness corresponds to the stress defined as $\sigma_{c d}$, which is calculated to be $85.42 \mathrm{MPa}$.

3.3.2. Determination of the Initiation Stress $\sigma_{c i}$. The initiation stress occurs between the closure stress and damage stress and is within the elastic section of the stress-strain curve, which is difficult to determine by intuitive methods. The crack initiation stress occurs when the crack volume strain changes from the compressed state to the expanded state. When the crack volume strain is used for calculation, the elastic modulus and Poisson's ratio are generally considered to be constant. However, under variable stress conditions (confining pressure and pore water pressure), the elastic constants of the force stage (compaction, elasticity) change; thus the crack volume strain calculated by this method is not rigorous. As shown in Figure 7(a), the prepeak curve can be divided into three stages, the elastic modulus and Poisson's ratio of each interval are calculated, and the crack volume strain is calculated by substitution into equation (5). The first point deviator stress is $21.81 \mathrm{MPa}$, the axial strain is $0.19 \%$, and the radial strain is $0.0261 \%$. The second deviator stress point is $104.40 \mathrm{MPa}$, the axial strain is $0.78 \%$, and the radial strain is $0.2738 \%$. The third deviator stress point is $117.53 \mathrm{MPa}$, the axial strain is $0.94 \%$, and the radial strain is $0.4243 \%$. Because the elastic modulus and Poisson's ratio of the connection point substantially change, which positively influences the continuity of the curve and result, it is smoothed according to the curve trend. Figure 7(b) shows a schematic diagram of volumetric crack strain and initiation stress of sandstone under triaxial pore water pressure. An increase in volumetric strain $\varepsilon_{v}$ implies that the volume is decreasing. During the crack closure stage, the difference between $\varepsilon_{v}$ and $\varepsilon_{v}^{e}$ increases. The total volume strain at the initial loading stage is the same as the crack volume strain, which indicates that the crack strain is dominated by low stress. The proportion of elastic volume strain gradually increases with increasing stress. After entering the elastic stage, the crack volume strain remains at a continuously increasing rate, which indicates that not only elastic deformation occurs in the elastic stage but also a certain amount of plastic deformation. Only elastic deformation is dominant, thus this stage shows overall elastic characteristics. When the sandstone enters the crack propagation stage, the total volumetric strain is cracked. The proportion of volumetric strain gradually increases and the growth rate of the total volumetric strain is slower than the growth rate of the elastic volumetric strain, which results in a downward trend. There is a turning point in the crack volumetric strain $\varepsilon_{v}^{c}$ from increasing to smaller values; the stress level corresponding to this point is the beginning crack stress $\sigma_{c i}$. If the initial cracking stress is an elastic segment, the cracking stress implies the beginning of volume expansion.

\section{Sandstone Characteristic Stress Changes under Variable Pore Water Pressure Conditions}

The curves under different confining pressure and pore water pressure conditions are analyzed according to the calculation methods of closure stress, crack initiation stress, and damage stress presented in Section 2. The closure stress is obtained according to the relationship between deviatoric stress and axial stiffness. The deviator stress and body stiffness yield the damage stress, and the crack initiation stress is obtained according to the crack volume strain. The crack propagation and evolution process are affected by the confining pressure and pore water pressure. Figure 8 shows the law of crack volume strain $\varepsilon_{v}^{c}$ under different pore water and confining pressure conditions. With increasing effective stress $\left(\sigma_{1}-\sigma_{3}-P\right)$, the initial closure amount of the sandstone gradually decreases and the elastic section shows an increasing trend. During the crack propagation stage, the slope of the curve decreases and the crack propagation speed becomes increasing slow. Under a fixed confining pressure $\left(\sigma_{3}=30 \mathrm{MPa}\right)$ and increasing pore water pressure, the crack closure and elastic phases are similar and the slope of the crack propagation phase are also similar, which indicates that the pore water pressure does not have a decisive effect on the crack evolution. The confining pressure in the crack propagation phase is the primary controlling factor.

Table 2 lists the sandstone peak deviatoric stress, closure stress, crack initiation stress, and damage stress values under different pore water and confining pressure conditions. Three dimensionless indexes $\sigma_{c c} / \sigma_{c}, \sigma_{c i} / \sigma_{c}$, and $\sigma_{c d} / \sigma_{c}$ are 


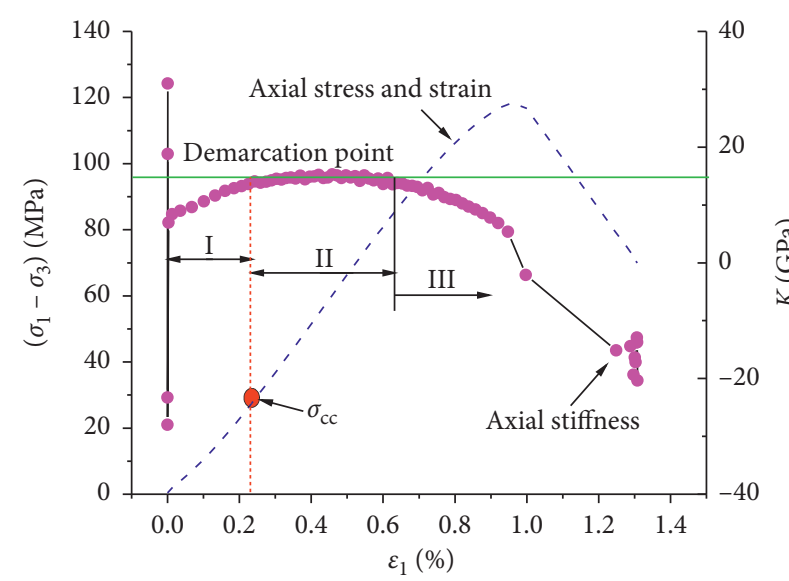

(a)

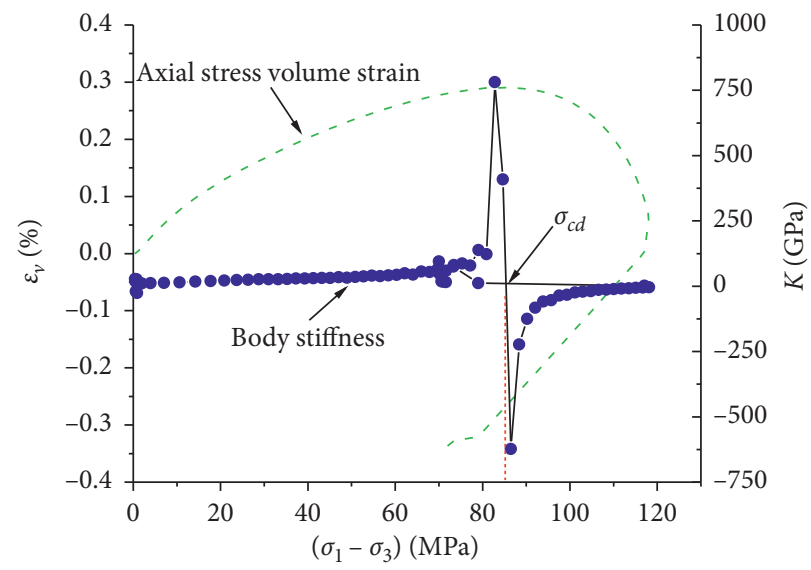

(b)

FIgure 6: Calculation method of characteristic stress. (a) Closed stress calculation curve; (b) damaged stress calculation curve.

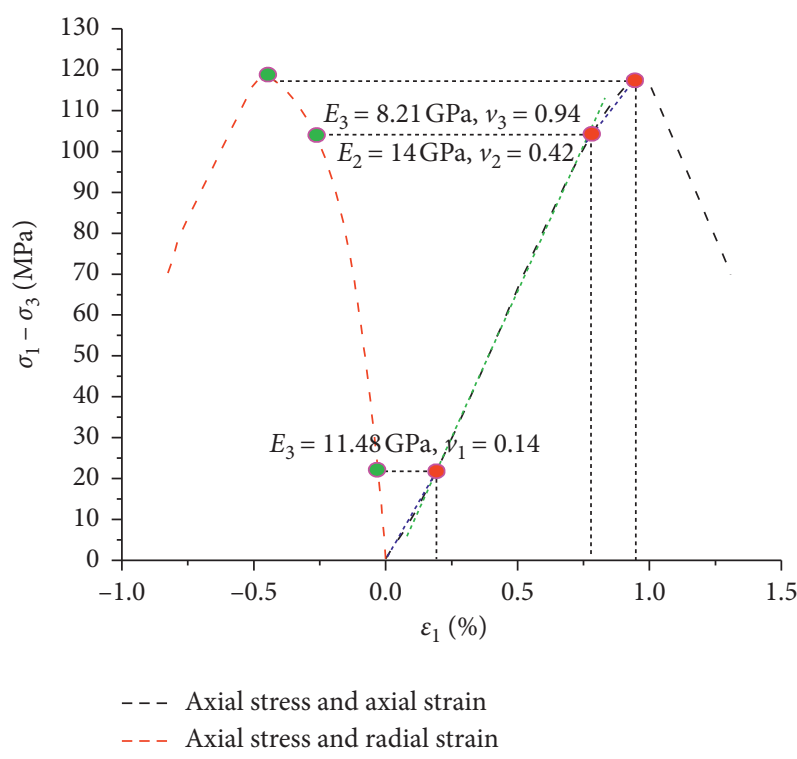

(a)

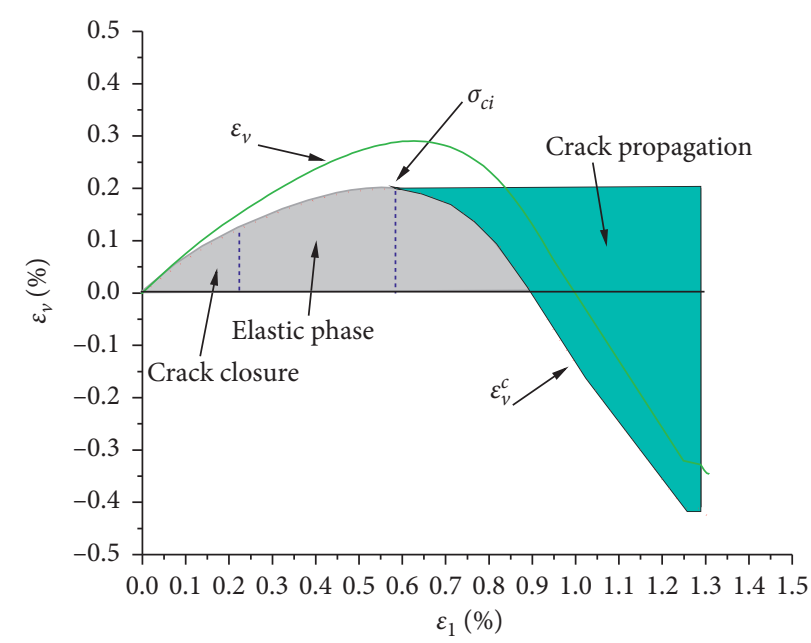

(b)

FIGURE 7: Calculation method of characteristic stress. (a) Modulus and strain aspect ratio at different stages. (b) Initiation stress calculation method.

added to investigate the confining pressure and influence of pore water pressure on the characteristic stress. The dimensionless $\sigma_{c i} / \sigma_{c}$ and $\sigma_{c c} / \sigma_{c}$, respectively, reflect the relative positions of the initiation stress and damage stress in the full stress-strain curve in the rock damage and failure process. The parameter $\sigma_{c d} / \sigma_{c}$ reflects the crack propagation speed from initiation to stable propagation. The numerical value of the characteristic stress changes significantly under the combined action of confining pressure and pore water pressure, and the relative value more accurately and objectively reflects the fracture process.

The characteristic stress change is based on the peak deviatoric stress; thus, we first analyze the change law of peak deviatoric stress under hydraulic-mechanical coupling.
Figure 9 shows the relationship curves of different confining pressures and pore water pressures with peak deviatoric and effective stresses. The peak deviatoric and effective peak deviatoric stresses show the same changing trend. The stress distribution is not regular due to the complex coupling stress conditions of confining pressure and pore water pressure. We therefore discuss the law of stress changes from three perspectives: fixed water pressure, fixed confining pressure, and sufficient confining pressure.

When the pore water pressure is fixed, such as in samples $10-5,20-5$, and $30-5$ and in samples $20-10$ and $30-10$, the peak deviator stress shows a linear growth trend with increasing confining pressure. The pore water pressure of the 5 and $10 \mathrm{MPa}$ curves show that the growth slopes are 


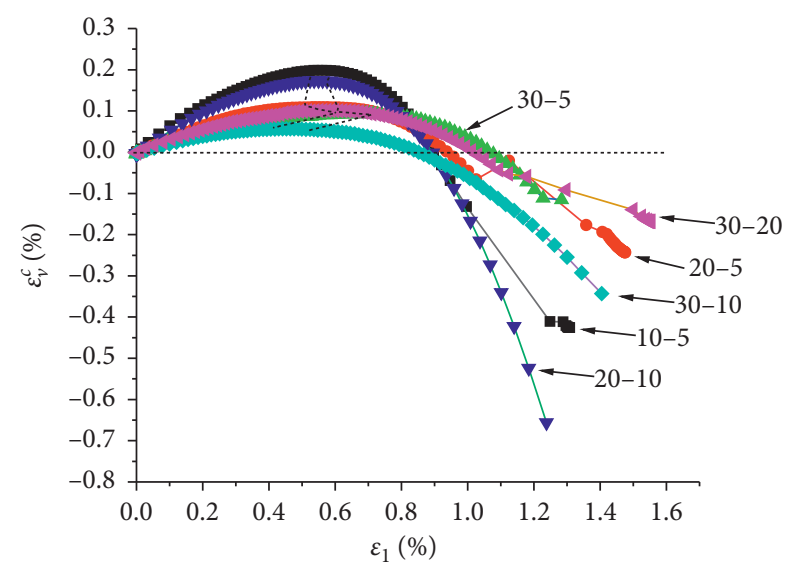

FIGURE 8: Variation of volumetric strain of different pore water cracks.

TABLE 2: Characteristic stress data table.

\begin{tabular}{lccccccc}
\hline Number & $\sigma_{c}(\mathrm{MPa})$ & $\sigma_{c c}(\mathrm{MPa})$ & $\sigma_{c i}(\mathrm{MPa})$ & $\sigma_{c d}(\mathrm{MPa})$ & $\left(\sigma_{c c} / \sigma_{c}\right) \%$ & $\left(\sigma_{c i} / \sigma_{c}\right) \%$ & $\left(\sigma_{c d} / \sigma_{c}\right) \%$ \\
\hline $10-5$ & 118.13 & 27.44 & 66.72 & 85.42 & 23.23 & 56.48 \\
$20-5$ & 139.26 & 28.80 & 81.42 & 113.44 & 20.68 & 58.47 \\
$30-5$ & 177.10 & 32.34 & 112.45 & 154.20 & 18.26 & 63.50 \\
$20-10$ & 133.84 & 26.68 & 71.66 & 90.89 & 19.93 & 53.54 \\
$30-10$ & 162.34 & 42.05 & 94.90 & 132.35 & 25.90 & 58.46 \\
$30-20$ & 155.21 & 40.30 & 87.24 & 124.28 & 25.96 & 57.07 \\
\hline
\end{tabular}

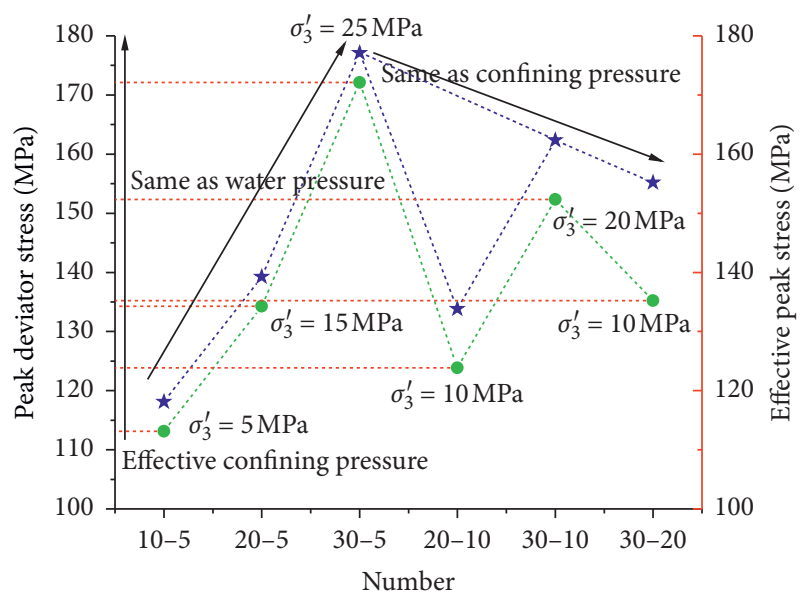

FIGURE 9: Variation law of deviatoric stress and effective stress under different confining pressure and pore water pressure conditions.

approximately equal, which satisfies the fundamental law of increasing strength with increasing lateral constraint. This also shows that pore water pressure has little effect on the sandstone strength change law.

When the confining pressure is fixed, such as in samples $30-5,30-10$, and 30-20, the deviatoric stress shows that the same water pressure slope is significantly higher than the same confining pressure slope. This indicates that, under same stress conditions, the effect of lateral restraint is higher than that of water pressure. The analysis of the overall effective peak deviatoric stress shows that with increasing effective confining pressure, the effective peak deviatoric stress clearly increases and the growth rate increases. Sample 30-20 shows a jump phenomenon possibly because the rock strength under high water pressure and high confining pressure coupling is mainly controlled by confining pressure, followed by the influence of water pressure, which is consistent with the analysis of the previously mentioned results.

According to the characteristic stress change law under different confining pressure and pore water pressure conditions in Figure 10, the trends of the closure stress $\sigma_{c c}$, initiation stress $\sigma_{c i}$, and damage stress $\sigma_{c d}$ are consistent with the peak deviator stress $\sigma_{c}$. The changing scale of closure stress $\sigma_{c c}$ is smaller than the cracking stress $\sigma_{c i}$ and less than the damage stress $\sigma_{c d}$. This indicates that the closure stress $\sigma_{c c}$ has the lowest sensitivity to confining pressure and pore water pressure, and the initiation stress $\sigma_{c i}$ is relatively sensitive. The damage stress $\sigma_{c d}$ is highly sensitive. Under fixed pore water pressure, the characteristic stress increases linearly with increasing confining pressure. Under fixed confining pressure, the initiation stress $\sigma_{c i}$ and damage stress $\sigma_{c d}$ decrease with increasing pore water pressure. However, the closure stress does not display an absolute law. As the effective confining pressure increases, the characteristic stress shows an increasing trend and the jump phenomenon remains in sample 30-20 but at a higher jump intensity than the peak deviatoric stress. The initiation of stress and damage stress corresponding to high water pressure and high confining pressure show a relative lag, which is not suitable for early warning and forecasting purposes. 


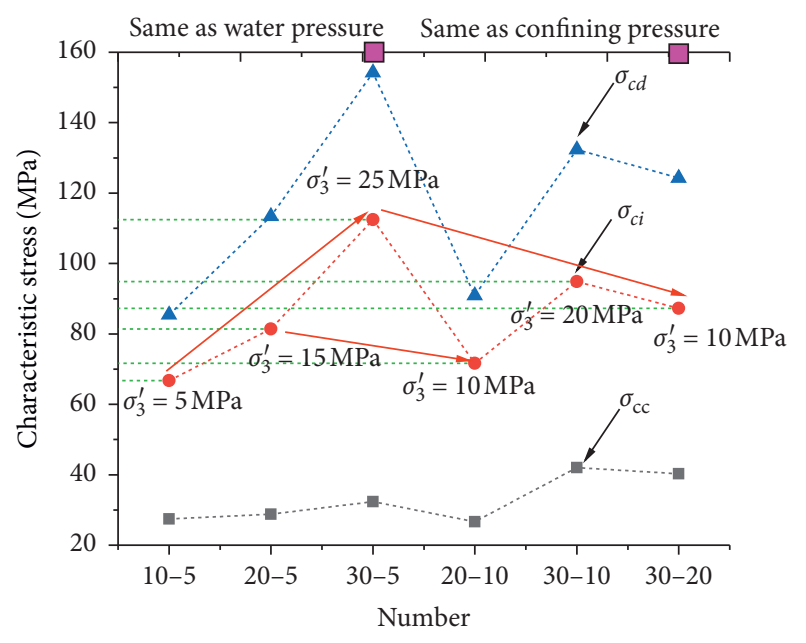

FIgURE 10: Variation law of characteristic stress under different confining pressure and pore water pressure conditions.

Figure 11 shows the ratio of characteristic stress to peak deviatoric stress under different confining pressure and pore water pressure conditions. The closure stress varies from $18.26 \%$ to $25.96 \%$, the initiation stress varies from $53.54 \%$ to $63.50 \%$, and the damage stress ranges from $67.91 \%$ to $87.07 \%$. The range of variation and band width in Figure 11 shows that the coupling of confining pressure and hydraulic pressure is less sensitive to closure stress, moderately sensitive to initiation stress, and more sensitive to damage stress. The characteristic stress corresponds to the degree of crack activity, which also explains the relationship between stress and crack activity. When the pore water pressure is constant, the closure stress decreases with increasing confining pressure, whereas the initiation stress and damage stress increase. When the confining pressure is constant, the closure stress shows a stable trend after increasing with increasing pore water pressure, and the initiation stress and damage stress show a stable trend after decreasing.

Table 3 lists the strain values and strain ratios corresponding to closure stress, crack initiation stress, damage stress, and peak deviatoric stress. Due to the influence of pore water pressure, the strain change law is more complicated, and thus the curve in Figure 12 is drawn for indepth analysis.

The particular strain and ratio are analyzed according to the curve change law in Figure 12. When the pore water pressure is constant, the closure strain and ratio decrease with increasing confining pressure, the crack initiation strain, failure strain, and ratio show increase, and the crack initiation stress initially decreases and then increases. The peak strain increases nearly linearly upon increasing pore water pressure and fixed confining pressure, whereas the closure strain and ratio initially increase and then decrease and the initiation strain decreases. The crack initiation strain ratio initially decreases and then increases, as do the damage stress and ratio, whereas the peak strain initially increases and then decreases. Different characteristic strains and ratios

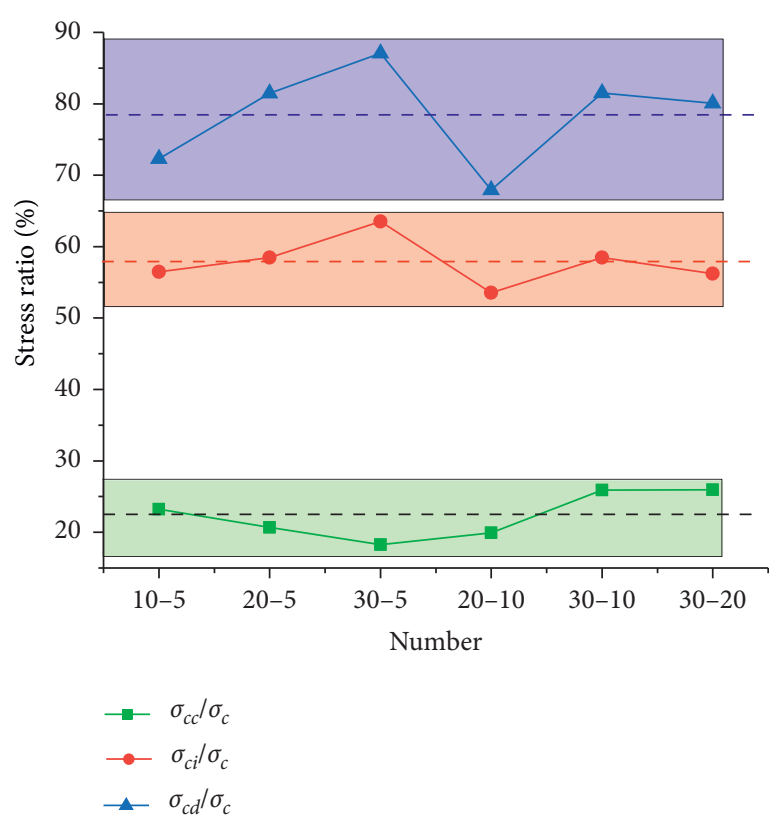

Figure 11: Variation law of characteristic stress ratio under different confining pressure and pore water pressure conditions.

TABLE 3: Data table of characteristic strain.

\begin{tabular}{lccccccc}
\hline Number & $\begin{array}{c}\varepsilon_{c} \\
(\%)\end{array}$ & $\begin{array}{c}\varepsilon_{c c} \\
(\%)\end{array}$ & $\begin{array}{c}\varepsilon_{c i} \\
(\%)\end{array}$ & $\begin{array}{c}\varepsilon_{c d} \\
(\%)\end{array}$ & $\begin{array}{c}\left(\varepsilon_{c c} / \varepsilon_{c}\right) \\
\%\end{array}$ & $\begin{array}{c}\left(\varepsilon_{c i} / \varepsilon_{c}\right) \\
\%\end{array}$ & $\begin{array}{c}\left(\varepsilon_{c c} / \varepsilon_{c}\right) \\
\%\end{array}$ \\
\hline $10-5$ & 0.95 & 0.26 & 0.51 & 0.64 & 27.37 & 53.68 & 67.37 \\
$20-5$ & 1.12 & 0.20 & 0.55 & 0.77 & 17.86 & 49.11 & 68.75 \\
$30-5$ & 1.28 & 0.19 & 0.68 & 0.98 & 14.84 & 53.13 & 76.56 \\
$20-10$ & 1.23 & 0.21 & 0.51 & 0.64 & 17.07 & 41.46 & 52.03 \\
$30-10$ & 1.40 & 0.28 & 0.61 & 0.89 & 20.00 & 43.57 & 63.57 \\
$30-20$ & 1.12 & 0.27 & 0.56 & 0.92 & 24.11 & 50.00 & 82.14 \\
\hline
\end{tabular}

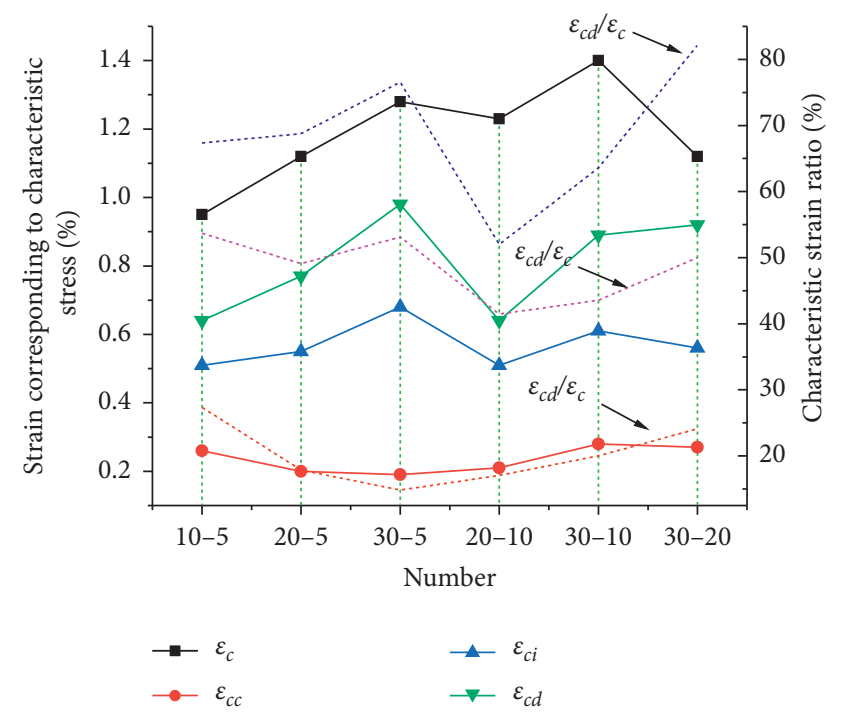

FIGURE 12: Variation law of characteristic strain and ratio under different confining pressure and pore water pressure conditions. 
have different changing laws, which indicates the different effects of water pressure. The influence of rock deformation is more complicated, and in-depth studies are required using more detailed experimental schemes.

\section{Sandstone Internal Modulus and Transverse- Radial Strain Ratio in the Characteristic Stress Stage under Variable Pore Water Pressure Conditions}

The rock modulus characterize the hardness characteristics under pressure, and the aspect ratio characterizes the overall rock deformation characteristics. The rock modulus and transverse and radial strain characteristics change under pore water pressure action, and different characteristic stress stages occur under different pore water pressure conditions. The feedback stiffness is inconsistent with the change law of the transverse and radial strain ratio, and the characteristic stress stage characteristics can also be fed back through the change of the stiffness and the transverse and radial strain ratio. The characteristic stress divides the prepeak deviatoric stress-strain curve into four typical stages: (I) initial loading to closure stress; (II) closure stress to initiation stress; (III) initiation stress to damage stress; and (IV) peak deviatoric stress. The second stage is in the elastic section and its corresponding parameters are the elastic modulus and Poisson's ratio. The fourth stage contains the information of the entire stress-strain curve, corresponding to the secant modulus. The modulus is calculated by the secant method and the radial strain calculates the aspect ratio to transverse strain.

Figure 13 shows the change rule of the modulus and transverse-radial strain ratio under different pore water and confining pressure conditions. The changing trend of the modulus and transverse-radial strain ratio shows clear differences and a negative correlation law. The modulus presents a dual-zone feature, with stages I, II, and III in one interval and stage IV in another. In stage I, the modulus is largely volatile. When the pore water pressure is $P=5 \mathrm{MPa}$, the closure modulus sharply increases with increasing confining pressure, which indicates that the lateral restraining force has a certain effect on the closure stiffness. When the confining pressure is $\sigma_{3}=30 \mathrm{MPa}$, the closure modulus initially decreases with increasing pore water pressure and then stabilizes. This indicates that low pore water pressure has a significant softening effect on the closure modulus of sandstone. However, under high pore water pressure, the impact on the closure modulus of sandstone is relatively weak and the method of increasing water pressure to weaken confining pressure properties should be used with caution. The modulus is consistent in stages II and III, and the high confining pressure $\left(\sigma_{3}=30 \mathrm{MPa}\right)$ has a certain degree of dispersion. The main reason is because stage II is in the elastic section as a whole and stage III is between elastic and plastic. This is a continuous process and the curvature changes slowly and smoothly. The slope of the stress-strain curve in stage III is therefore similar to that in stage II. The calculated result in

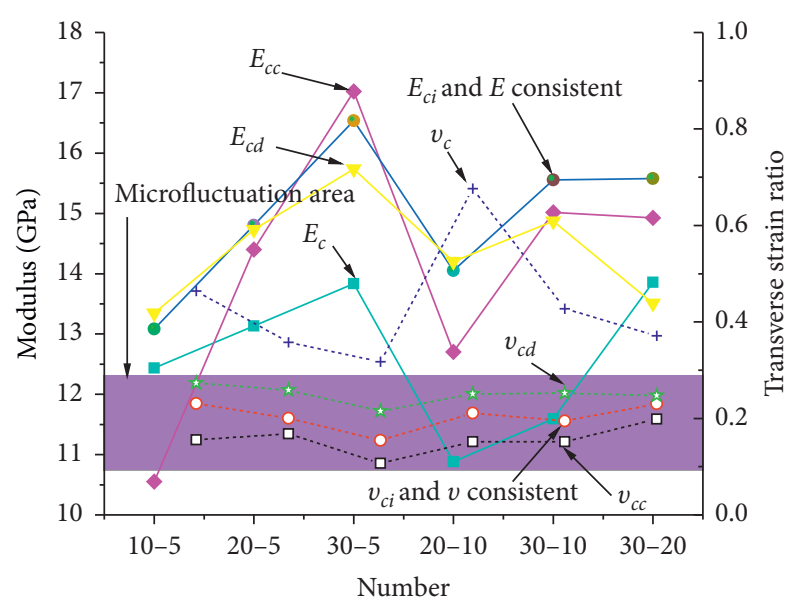

Figure 13: Variation law of modulus and transverse-to-radial strain ratio under different confining pressure and pore water pressure conditions.

stage II is consistent with the elastic modulus and its change law and trend are consistent with the closed modulus; however, the volatility is more stable. In stage IV, the secant modulus values are all smaller than the other moduli. However, their changing trends are consistent and only at high water pressure $(P=20 \mathrm{MPa})$ and high confining pressure $\left(\sigma_{3}=30 \mathrm{MPa}\right)$ conditions does the modulus present an inconsistent law. The transverse-to-radial deformation ratio also presents two characteristic zones. Stage IV shows a clearly negative correlation with the modulus. Stages I, II, and III are in the microfluctuation interval and the transverse-to-vertical deformation ratio has the characteristics of III $>$ II $>$ I but changes within the stage and the amplitude is smaller. At constant pore water pressure, the transverse and radial deformation ratio decreases with increasing confining pressure. At constant confining pressure, the transverse and radial deformation ratio increases with increasing pore water pressure. Pore water pressure and confining pressure have little effect on the transverse and radial deformation ratios in stages I, II, and III, and the deformation ratio can be considered unchanged in the calculation process. Pore water pressure and confining pressure have a greater influence on the transverse and radial deformation ratio in stage IV. The overall analysis shows that the moduli in stages I, II, and III are similar to the law of the transverse and radial deformation ratio, with notable differences between stage IV and the other stages. When the modulus and transverse deformation ratios are selected for calculation, closure, cracking, and one of the damage intervals can be selected, which also illustrates the availability of the elastic modulus and Poisson's ratio.

\section{Analysis of the Sandstone Fracture Mechanism}

With the development and application of some new surface and internal detection technologies, rock fracture research methods have emerged that are supported by microscopic observations (CT loading system, optical microscopic 
observation system, and synchronous high-speed camera system), as well as $\mathrm{AE}$ and electromagnetic radiation. A previous study reported that rock fracturing begins locally; however, the failure mechanism caused by the axial compressive stress remains controversial. Lian et al. [26] studied the microscopic failure process of granite slabs under uniaxial compression and found that the occurrence and development of axial cracks (tension cracks) eventually led to splitting failure. You [27] proposed that the rock failure form under uniaxial compression is generally tensile along the axial direction; however, tensile failure is caused by shear slip.

The fracture types of the three-axis conventional loading experiment rock are all typical single oblique shear failures, which can be simplified to a two-dimensional axisymmetric form. A schematic failure diagram is shown in Figure 14. Rock failure is composed of elastic deformation bodies and plastic deformation bodies. The elastic body only affects the rock shape (e.g., deformation of the upper and lower parts of the shear line) and plastic deformation affects the rock sliding dislocation (e.g., movement of the upper part of the shear line). The direction of rock cracking and fracture angle can therefore be predicted if the evolution laws and trends of axial plastic deformation and lateral expansion plastic deformation are known. According to the calculation approach of volumetric strain presented in Section 2.2, the axial crack strain is determined, the total axial strain $\varepsilon_{1}$ is obtained experimentally, the knowledge of elastic mechanics can be used to calculate the axial elastic strain $\varepsilon_{v 1}^{e}$, and the difference of the data yields the axial crack strain $\varepsilon_{v 1}^{e}$. The radial crack strain cannot be calculated using the methods mentioned above but rather indirectly using the relationship between volume crack strain, axial crack strain, and radial crack strain.

Figure 15 shows the variation law of the total axial strain, axial elastic strain, and axial crack strain of sample 10-5. The nonlinearity in the closing stress stage leads to the rapid growth of the axial crack strain. Although the total axial strain curve is not linear in the elastic stage, the axial elastic strain is linear, which causes the axial crack strain to fluctuate over a small range. The axial crack strain shows a decreasing trend during the initiation stress stage. The axial crack strain during the failure stress stage shows an accelerated growth trend, and the crack is in an unstable growth stage. Figure 16 shows the variation law of the radial crack strain of sample $10-5$. The overall variation law and trend are consistent with the axial crack strain. However, the inflection point of the radial crack strain is higher than that of the axial crack strain, which indicates the occurrence of radial cracks. Before the axial direction, this can be interpreted as crack initiation along the axial direction. The initiation of cracking in sandstone with pore water can therefore preliminarily be considered tensile failure. The axial crack strain and radial crack strain accelerate and increase with increasing axial stress after passing through the crack initiation point, which indicates that new cracks have occurred in the axial and radial directions. The crack strain shows that the main control crack will deviate from the axial direction by a given angle. The ratio of the axial and radial

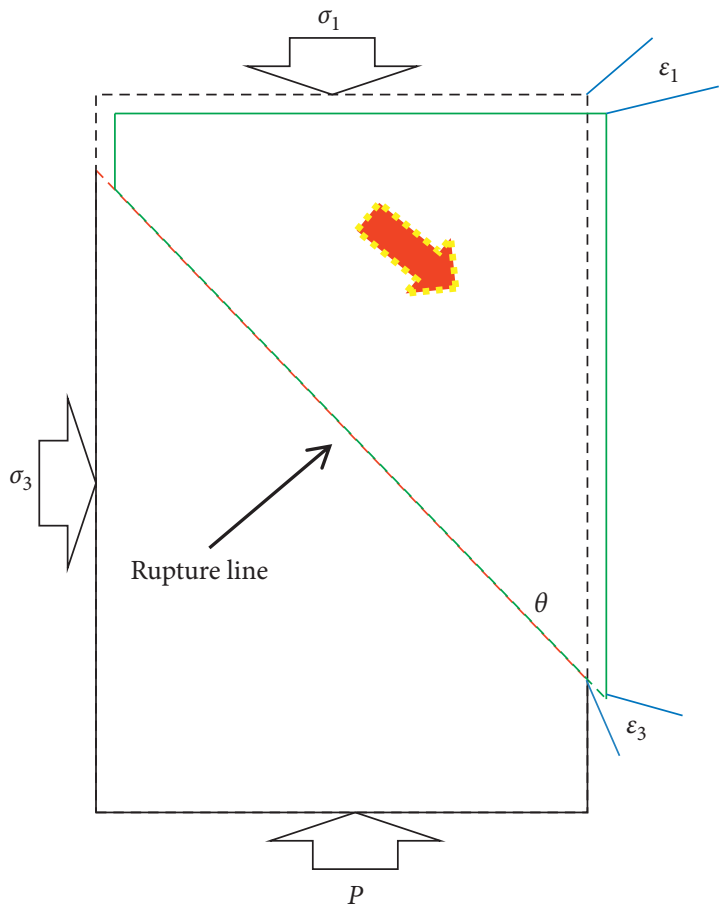

FIGURE 14: Schematic diagram of typical rock failure under triaxial compression.

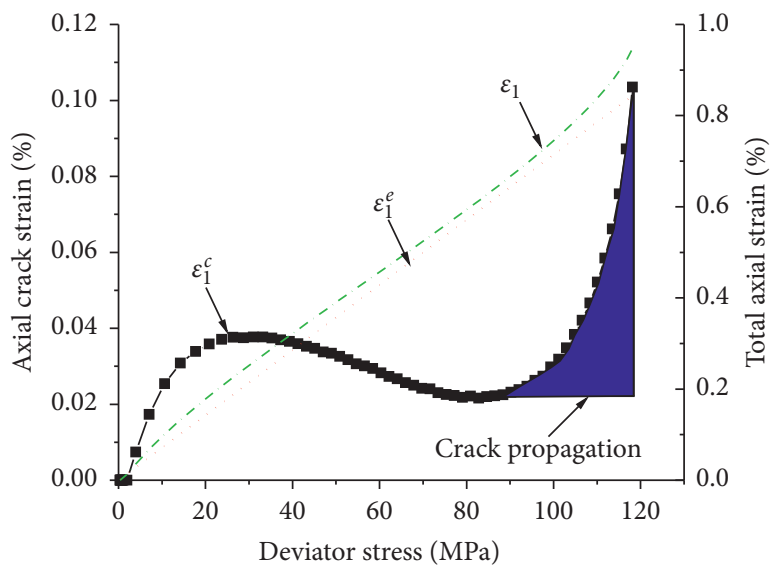

Figure 15: Axial crack strain curve of sample 10-5.

crack strain is the fracture trend angle. However, both the axial crack strain and radial crack strain show an accelerated growth trend during the unstable crack propagation stage. The ratio of axial and radial crack strain should therefore be discussed and analyzed in depth.

The results in Figure 14 show that the ratio of axial crack strain and radial crack strain during the stable crack propagation stage can be used to determine the fracture trend angle using the arctangent function. The relationship between the axial crack strain and fracture trend is thus obtained in Figure 17. According to its changing law, the fracture trend angle is found to rapidly decrease and then stabilize with increasing degree of crack evolution. The curve change trend satisfies the Allometricl model, and the fracture 


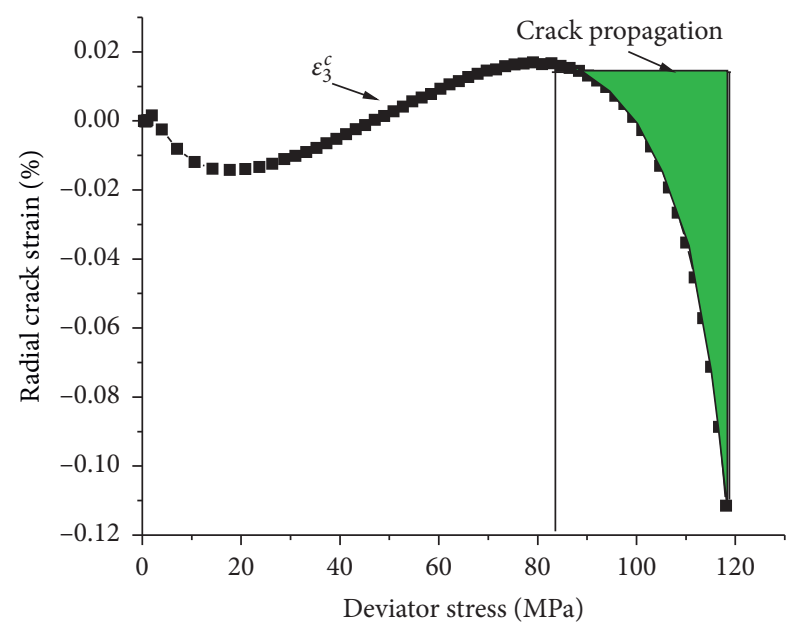

FIGURE 16: Rock radial crack strain curve of sample 10-5.

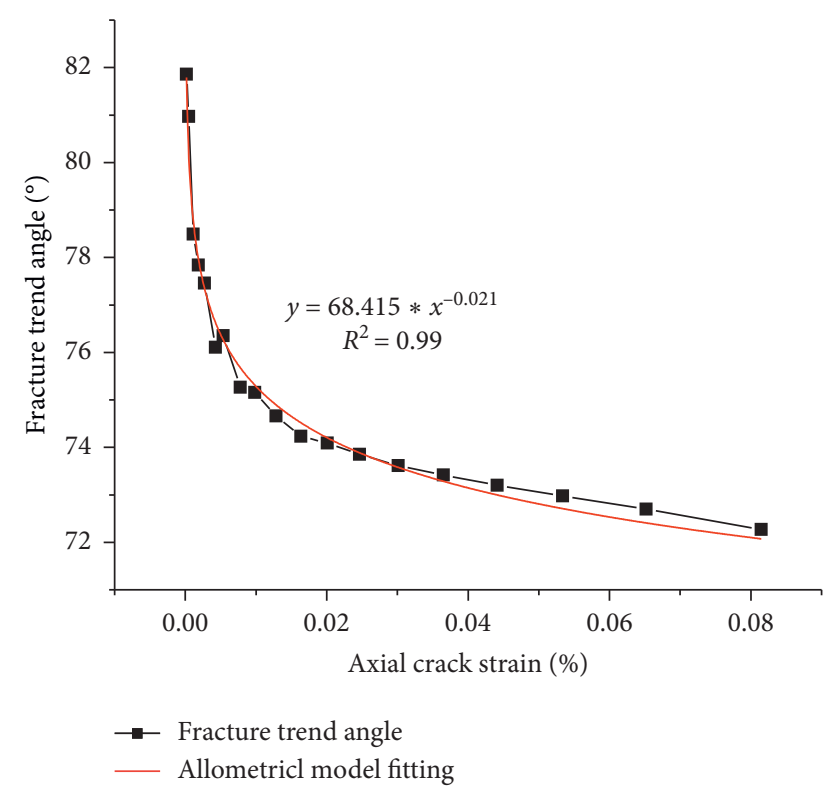

Figure 17: Radial crack strain curve of sample 10-5.

trend angle is approximately $68.4^{\circ}$, as determined by limit analysis. Figure 18 shows a photograph of the fractured 10-5 sample, which presents typical oblique shear failure [28, 29]. The upper part of the fracture presents a nonlinear external deviation, the lower part presents a radial splitting failure, and the middle part satisfies the linear fracture. The main body adds a trend line and the macrofracture angle is approximately $70^{\circ}$. This shows that the evolution trend of the axial crack and radial crack strains can be used to characterize the crack fracture angle trend with more reliable results.

According to the results and methods presented here, the fracture trend angles are obtained under different confining pressure and pore water pressure conditions. The corresponding fracture angles are measured from the experimental results, as shown in Figure 19. The actual fracture angle varies from $63^{\circ}$ to $72^{\circ}$, and the fracture trend angle varies from $61^{\circ}$ to $71^{\circ}$. The overall predicted fracture angle is

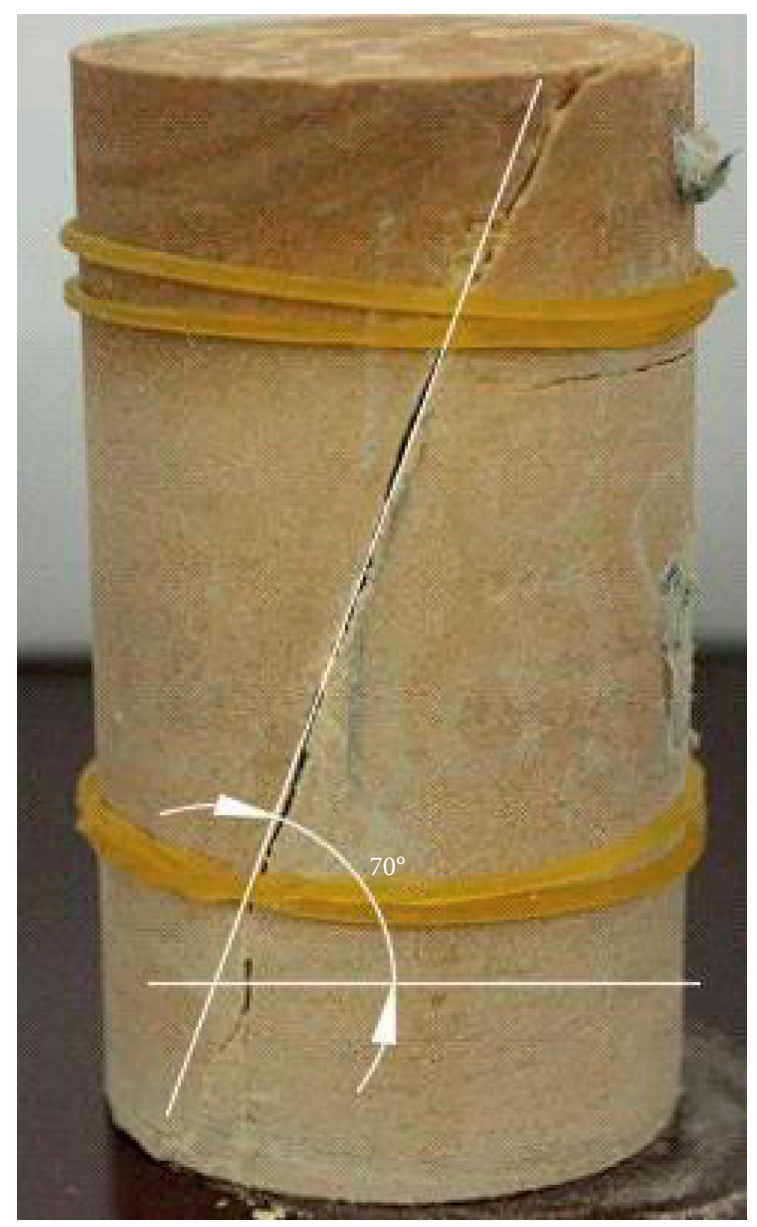

FIGURE 18: Rock fracture shape and angle of sample 10-5.

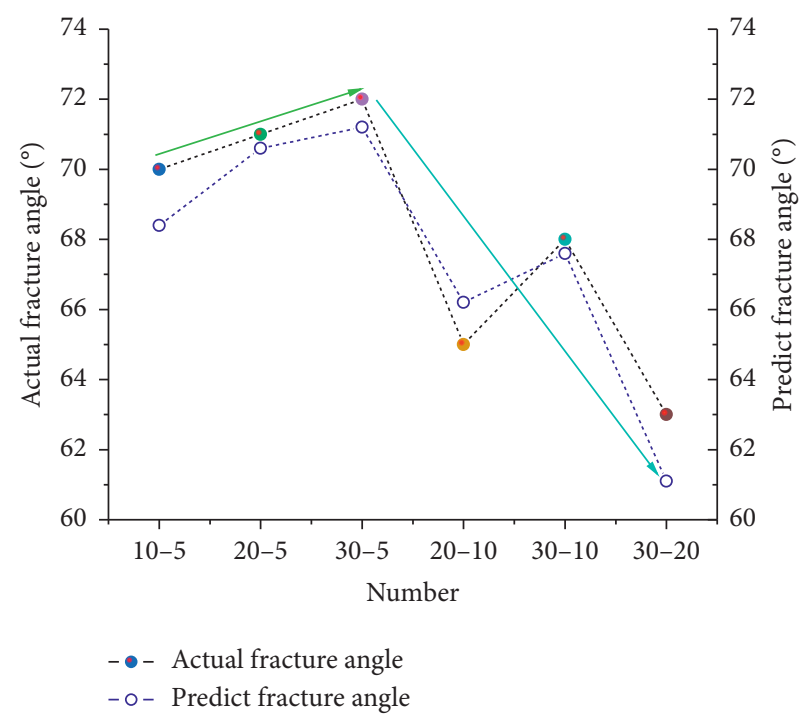

FIGURE 19: Relationship between the actual fracture angle and fracture trend angle under different pore water pressure and confining pressure conditions.

smaller than the actual fracture angle. This may be because the radial crack strain is the crack strain measured in the middle position instead of the value of the overall transverse 
change because the radial crack strain is smaller than the actual transverse crack strain. This explains the difference between the theoretical results and the actual fracture angle. Under constant pore water pressure, both the fracture trend angle and actual fracture angle gradually increase with increasing confining pressure. This indicates that higher confining pressure is associated with greater binding forces on the hoop, more difficult lateral expansion, and higher fracture angles. When the pressure is constant, both the fracture trend angle and actual fracture angle gradually decrease with increasing pore water pressure. This indicates that the pore water pressure forms tensile stress in the rock. The lateral expansion is more natural and results in a smaller fracture angle. The effect of water pressure on the crack inclination is higher than that of the confining pressure, which also explains the difference between internal tension and external pressure.

In summary, the crack propagation of sandstone under pore water action and confining pressure can be considered to mainly manifest as a shear failure. The internal cracks are mainly type-II cracks and type-I cracks are locally present. After the initiation stress, the crack initiates at a certain angle and rapidly falls back and adjusts within a specific range. After damage stress, the crack expands and extends at an angle close to the real fracture. The final fracture surface angle is combined by the influence of confining pressure and pore water pressure.

\section{Conclusion}

We used a ROCK600-50 triaxial rock mechanics experimental system to study the progressive failure characteristics and mechanisms of sandstone under different pore water pressure and confining pressure coupling paths. The following conclusions are obtained:

(1) The closing stress $\sigma_{c c}$ is determined by the boundary point of the axial stiffness change. The damage stress $\sigma_{c d}$ is determined by the fluctuation of volume stiffness. The crack initiation stress $\sigma_{c i}$ is determined by the zero points of the volume crack strain tangent.

(2) With increasing effective stress, the initial closure of the volumetric crack strain in sandstone gradually decreases and the elastic section shows an increasing trend. With increasing pore water pressure, the sandstone volumetric crack strain yields similar values in the crack closure and elastic stage and the slope of the crack propagation section is similar. The pore water pressure does not have a decisive effect on the crack evolution and propagation. The confining pressure is the main controlling factor in the crack propagation stage.

(3) With increasing effective confining pressure, the effective peak deviatoric stress shows an apparent increasing trend. The rock strength under the coupling of high water pressure and high confining pressure is strongly affected by confining pressure. The characteristic stress shows a linear growth trend with increasing confining pressure. The initiation stress $\sigma_{c i}$ and damage stress $\sigma_{c d}$ decrease with increasing pore water pressure.

(4) The moduli in stages I, II, and III are similar to the law of the transverse and radial deformation ratio. This also demonstrates the availability of the elastic modulus and Poisson's ratio.

(5) The crack propagation of sandstone under pore water action and confining pressure is mainly manifested as shear failure. The internal cracks are mainly type-II cracks with local type-I cracks. The final fracture surface angle is combined with the influence of confining pressure and pore water pressure.

\section{Data Availability}

The data used to support the findings of this study have not been made available because the original data relate to the intellectual property rights of the author, and all the original data cannot appear in the paper, and the experimental data that cannot appear is related to privacy.

\section{Conflicts of Interest}

All authors declare no conflicts of interest.

\section{Acknowledgments}

This research was supported by the National Natural Science Foundation of China (no. 51874002), National Key Research and Development Program (no.2016YFC0600901), Natural Science Foundation of Heilongjiang Province (nos.LH2019E087 and YQ2019E033), and basic scientific research business expenses of Provincial Undergraduate Colleges and Universities in Heilongiiang Province (no. Hkdqg201903).

\section{References}

[1] B. Li, W. Zhu, Y. Lei et al., "Experimental research on propagation mode of $3 \mathrm{D}$ hollow crack and material failure strength under hydro-mechanical coupling," Journal of Central South University, vol. 50, no. 5, pp. 1192-1202, 2019.

[2] Z. Liu, C. Zhou, Y. Lu et al., "Development of the multi-scale mechanical experimental system for rheological damage effect of soft rock bearing the hydro-mechanical coupling action," Rock and Soil Mechanics, vol. 39, no. 8, pp. 3077-3086, 2018.

[3] M. Cai, P. K. Kaiser, Y. Tasaka, T. Maejima, H. Morioka, and M. Minami, "Generalized crack initiation and crack damage stress thresholds of brittle rock masses near underground excavations," International Journal of Rock Mechanics and Mining Sciences, vol. 41, no. 5, pp. 833-847, 2004.

[4] O. Tang, Study on Mechanical Properties and Constitutive Model of Hard Rock under Hydro-Mechanical Coupling Condition, Chengdu University of Technology, Chengdu, China, 2017.

[5] W. Chen and J. Lei, "Study on creep characteristics of claystone under thermo-hydro-mechanical coupling," Rock and Soil Mechanics, vol. 41, no. 2, pp. 379-388, 2020. 
[6] H. Lyu and X. Lin, "Study on rock visco-elastic plasticity analysis and yield criterion of water and rock interaction," Coal Science and Technology, vol. 46, no. 12, pp. 107-112, 2018.

[7] J. Wang, J. Wang, T. Gu et al., "Research on the deformation characteristics of the surrounding rock about hipparion red clay under the action of water-force coupling," Journal of Engineering Geology, vol. 24, no. 6, pp. 1157-1169, 2016.

[8] W. Mang, Study on Mechanical Properties of Water Saturated Sandstone under Hydro Mechanical Coupling, Hunan University of Science and Technology, Xiangtan, China, 2017.

[9] K. Mu and J. Yu, "Acoustic emission of sandstone with hydromechanical coupling and pfc-based modelling of energy dissipation," Rock and Soil Mechanics, vol. 36, no. 5, pp. 1496-1504, 2015.

[10] G. Zhang, Study on True Triaxial Rockburst Test and Rockburst Criterion under Hydro-Mechanical Coupling Action, Chengdu University of Technology, Chengdu, China, 2016.

[11] N. Xie, L. Xu, J. Shao et al., "Coupled hydro-mechanical modeling of rock fractures subject to both normal stress and fluid pressure," Chinese Journal of Rock Mechanics and Engineering, vol. 30, no. 2, pp. 3796-3803, 2011.

[12] Z. Zhu, Q. Shen, X. Leng et al., "Study on crack initiation mechanism of three gorges granite," Chinese Journal of Rock Mechanics and Engineering, vol. 26, no. 12, pp. 2570-2575, 2007.

[13] Q. Liu, Y. Hu, and B. Liu, "Progressive damage constitutive models of granite based on experimental results," Rock and Soil Mechanics, vol. 30, no. 2, pp. 289-296, 2009.

[14] H. Wang, P. Fan, M. Wang et al., "Influence of strain rate on progressive failure process and characteristic stresses of red sandstone," Rock and Soil Mechanics, vol. 32, no. 5, pp. 1340-1346, 2011.

[15] C. Li, H. Xie, and L. Xie, "Experimental and theoretical study on the shale crack initiation stress and crack damage stress," Journal of China Coal Society, vol. 42, no. 4, pp. 1969-1976, 2017.

[16] G. Liu, F. Xiao, Q. Cheng et al., "Experimental study on acoustic emission characteristics of dry and saturated basalt columnar joints under uniaxial compression and tensile damage," Shock and Vibration, vol. 2019, Article ID 4971695, 12 pages, 2019.

[17] F. Xiao, G. Liu, and Q. Cheng, "Study on mechanical properties and damage evolution law of secondary destruction induced by simultaneous unloading after the peak of the curve of sandstone," Shock and Vibration, vol. 2018, Article ID 9524248, 17 pages, 2018.

[18] F. Xiao, G. Liu, and H. Wang, "Study on multiparameter precursory information identification of the fracture of yellow sandstone," Advances in Civil Engineering, vol. 2019, Article ID 7676801, 15 pages, 2019.

[19] G. M. Fonseka, S. A. F. Murrell, and P. Barnes, "Scanning electron microscope and acoustic emission studies of crack development in rocks," International Journal of Rock Mechanics and Mining Sciences \& Geomechanics Abstracts, vol. 22, no. 5, pp. 273-289, 1985.

[20] J. Ren, "Real-time CT monitoring for the meso-damage propaga-tion characteristics of rock under triaxial compression," Journal of Experimental Mechanics, vol. 16, no. 4, pp. 387-395, 2001.

[21] E. Eberhardt, D. Stead, B. Stimpson et al., "Changes in acoustic event properties with progressive fracture damage," International Journal of Rock Mechanics and Mining Sciences, vol. 34, no. 3, pp. 7-2, 1997.
[22] F. Amann, E. A. Button, K. F. Evans, V. S. Gischig, and M. Blümel, "Experimental study of the brittle behavior of clay shale in rapid unconfined compression," Rock Mechanics and Rock Engineering, vol. 44, no. 4, pp. 415-430, 2011.

[23] E. Eberhardt, D. Stead, and B. Stimpson, "Quantifying progressive pre-peak brittle fracture damage in rock during uniaxial compression," International Journal of Rock Mechanics and Mining Sciences, vol. 36, no. 3, pp. 361-380, 1999.

[24] L. Xue, S. Qin, Q. Sun, Y. Wang, L. M. Lee, and W. Li, "A study on crack damage stress thresholds of different rock types based on uniaxial compression tests," Rock Mechanics and Rock Engineering, vol. 47, no. 4, pp. 1183-1195, 2014.

[25] G. Liu, F. Xiao, and Q. Tao, "Rock mechanics characteristics and acoustic emission rule under small-size effect," Chinese Journal of Rock Mechanics and Engineering, vol. 21, no. 7, pp. 940-947, 2002.

[26] L. I. Lian, Y. Tsui, P. K. K. Lee et al., "Progressive cracking of granite plate under uniaxial compression," Chinese Journal of Rock Mechanics and Engineering, vol. 37, no. 2, pp. 3905-3917, 2018.

[27] M. You, Mechanical Properties of Rock, Geological Publishing House, Beijing, China, 2007.

[28] Z. Zhao, M. Zhang, Q. Ma, and B. Chen, "Deviation effect of coaxiality on the rock brazilian split," Advances in Mathematical Physics, vol. 2020, Article ID 5782457, 8 pages, 2020.

[29] Z. Zhao, W. Sun, M. Zhang, X. Gao, and S. Chen, "Fracture mechanical behavior of cracked cantilever roof with large cutting height mining," Shock and Vibration, vol. 2020, Article ID 1641382, 10 pages, 2020. 